\title{
Enfezamentos vermelho e pálido: Doenças em milho causadas por molicutes
}

\author{
Maize bush stunt and corn stunt: Diseases of corn caused by molicutes
}

\author{
Nelson Sidnei Massola Júnior ${ }^{1}$
}

\begin{abstract}
Resumo: Os enfezamentos vermelho e pálido são doenças do milho causadas, respectivamente, por um fitoplasma ("maize bushy stunt phytoplasma") e pelo Spiroplasma kunkelii, organismos restritos ao floema das plantas infectadas. Ambas são transmitidas pela cigarrinha Dalbulus maidis. São doenças bastante destrutivas, podendo causar sérios prejuízos aos agricultores. A importância dessas doenças aumentou muito nos últimos anos, devido principalmente aos cultivos "safrinha", que perpetuam o milho, os patógenos e o vetor no campo durante o ano todo. As plantas doentes exibem redução de crescimento, avermelhamento ou amarelecimento, proliferação excessiva de espigas pequenas e improdutivas, além de outros sintomas. No entanto, esses sintomas dependem do agente causal, condições climáticas e genótipo do milho. A diagnose correta tem sido feita por testes de ELISA ("enzyme-linked immunosorbent assay") e por PCR ("polymerase chain reaction"), devido à complexidade da sintomatologia. Nas áreas onde ocorrem, o controle dessas doenças baseia-se principalmente no uso de genótipos resistentes de milho.
\end{abstract}

Palavras-chave: Enfezamento, molicutes, milho, Spiroplasma kunkelii, phytoplasma.

\begin{abstract}
Maize Bushy Stunt and Corn Stunt are diseases of corn caused respectively by a phytoplasma (maize bushy stunt phytoplasma) and by Spiroplasma kunkelii. Both agents are restricted to the floem vessels of diseased plants. The leafhopper Dalbulus maidis is the vector of the diseases. The diseases are very harmfull to corn crops and can cause severe losses. Their importance increased very much in the last years mainly due to the continuous crops, which allow the perpetuation of corn, pathogens and vector over the year. Diseased plants show shortening, redening or yellowing and excessive proliferation of ears, among others symptoms. However, symptoms are variable according to the causal agent, environmental conditions and corn genotype. Correct diagnosis of the diseases has been reached with ELISA ("enzyme-linked immunosorbent assay") and PCR ("polymerase chain reaction"). The use of resistant genotypes of corn is the main strategy of control of the diseases.
\end{abstract}

Key words: Corn crops, molicutes, Spiroplasma kunkelii, phytoplasma.

\section{Situação Atual da Produção de Milho no Brasil}

O milho é uma das principais culturas do Brasil, onde contribui com mais de um terço de toda a produção de cereais e oleaginosas (PINAZZA, 1993). É amplamente distribuída e tem mostrado significativos aumentos, tanto na produtividade como em área cultivada (ALMEIDA, 1993; MAGALHÃES et al., 1995). A área cultivada apresentou um aumento de $20 \%$ nos últimos 20 anos, passando dos 10 milhões de hectares em 1973 para aproximadamente 12 milhões de hectares atualmente. Nesse mesmo período, a produção teve um aumento de mais de $100 \%$, passando de 14 para 30 milhões de toneladas em 1993 (ANUÁRIO ESTATÍSTICO DO BRASIL, 1975, 1995). Esse acréscimo na produção deveu-se à utilização de híbridos mais produtivos, técnicas mais adequadas para condu-ção da cultura e da realização de plantios adicionais, em épocas não convencionais de cultivo. Os plantios "safrinha", ou os extemporâneos de milho, realizados após a retirada da cultura de primavera-verão (GERAGE; BIANCO, 1990; DUARTE, 2001), apresentaram aumento de cerca de $100 \%$ na área cultivade e, de mais de $400 \%$ na produção nos últimos anos. Atualmente, esse sistema de cultivo atinge cerca de 2,2 milhões de hectares e contribui com 5 milhões de toneladas de grãos, representando aproximada-mente $19 \%$ da produção nacional de milho. O Paraná é o maior produtor nessa modalidade onde contribui com $28 \%$ da produção total do Brasil, seguido por São Paulo, com 14\% (TSUNECHIRO; GODOY, 2001).

Esse sistema de cultivo tem gerado problemas de ordem sanitária, anteriormente não observadas ou de menor ocorrência, quando eram realizadas semeaduras, apenas na época convencional. Considerando o clássico triângulo de doenças de plantas, onde hospedeiro, patógeno e ambiente estão em íntima relação, tem sido demonstrado inúmeras vezes que qualquer alteração num desses componentes leva a mudanças no patossistema como um todo. Com a cultura do milho não seria diferente. A presença da cultura no campo, durante praticamente 0 ano todo, alterou o comportamento de determinadas doenças, expondo os produtores a situações até então inexistentes (SILVA et al., 2001). Essa afirmação é verdadeira principalmente para aquelas doenças cujos agentes são transmitidos por insetos, a exemplo dos enfezamentos vermelho e pálido.

\footnotetext{
1 Professor Adjunto, Departamento de Agronomia/ CCA - Universidade Estadual de Londrina. Caixa Postal 6001, CEP 86051-970 Londrina, PR. E-mail: <nmassola@uol.com.br>
} 
A maior importância dessas doenças nos cultivos tardios e "safrinha", está relacionada com o aumento da população do inseto vetor nessa época (FERNANDES; BALMER, 1990; SILVA et al., 1991; WAQUIL, 1997). Esta situação se acentua quando a cultura anterior também era o milho. Nessa condição, a população dos vetores é maior e migra para as culturas mais novas, causando severas epidemias dos enfezamentos nesses cultivos tardios.

\section{Distribuição Geográfica e Importância dos Enfezamentos}

O primeiro registro dessas doenças foi na década de 40, no estado norte-americano do Texas (ALTSTATT, 1945). Atualmente, além dos Estados Unidos, existem relatos no México (DAVIS, 1973; GORDON et al., 1985; BAJET; RENFRO, 1989), Nicarágua (HRUSKA et al., 1996), Venezuela (LASTRA; TRUJILLO, 1976), Peru (NAULT et al., 1979; NAULT et al., 1981) e Paraguai (LEZCANO; MACHADO, 1997). No Brasil, são conhecidas desde o início da década de 70 (COSTA et al., 1971), quando foram consideradas de importância secundária. Entretanto, já naquela época alertava-se para os sérios prejuízos que poderiam causar caso o milho fosse plantado tardiamente. Essa tendência de maiores danos em plantios tardios foi verificada por Altstatt (1945) desde a primeira descrição feita por esse mesmo autor. A partir de então, ambos os enfezamentos têm causado epidemias nos Estados Unidos (BRADFUTE et al., 1981), Nicarágua (HRUSKA et al., 1996) e Brasil (OLIVEIRA et al., 1998). Os prejuízos podem chegar a 100\%, dependendo da suscetibilidade dos genótipos semeados (SCOTT et al., 1977; OLIVEIRA et al., 1998). No Brasil, estudos recentes, em condições de campo, revelaram que, quanto mais cedo se manifestem os sintomas nas plantas, maiores são os prejuízos. Esses mesmos estudo mostraram que, para cada $1 \%$ de aumento na incidência dessas doenças, em híbridos suscetíveis, ocorre 0,8\% de redução na produção (MASSOLA JúNIOR et al., 1999a). Em estudos realizados em condições de telado à prova de insetos, um híbrido suscetível teve sua produção reduzida em $64 \%$ quando inoculado, com o Spiroplasma kunkelii, agente causal do enfezamento pálido, por meio de insetos infectivos aos 10 dias após a emergência (MASSOLA JÚNIOR et al., 1999b). Os resultados indicam que essas enfermidades podem reduzir de maneira significativa a produção do milho.

\section{Etiologia}

Desde o primeiro relato, acreditou-se que essas doenças fossem de etiologia viral (MARAMOROSCH, 1958). Por volta de 1970, descobriu-se que os agentes causais eram dois molicutes, sendo o enfezamento pálido ("Corn Stunt") causado pelo espiroplasma Spiroplasma kunkeliie o enfezamento vermelho ("Maize Bushy Stunt") associado a um organismo do tipo micoplasma, atualmente chamado de fitoplasma (GRANADOS, 1969; CHEN; GRANADOS, 1970; DAVIS et al., 1972;
CHEN; LIAO, 1975; WILLIAMSON; WHITCOMB, 1975). Ambos são organismos sem parede celular, com apenas uma membrana unitária envolvendo o citoplasma. São encontrados restritos ao floema de plantas doentes e sensíveis à tetraciclina, porém não à penicilina (BEDENDO et al., 1995; AGRIOS, 1997).

O S. kunkelii agente causal do enfezamento pálido foi encontrado pela primeira vez em 1972, em plantas infectadas (DAVIS et al., 1972), sendo essa a primeira constatação de organismos com morfologia helicoidal em plantas (Figura 1). Um ano mais tarde, o termo "spiroplasma" foi proposto para designar tais organismos (DAVIS; WORLEY, 1973). Mas somente em 1986, após estudos detalhados de morfologia, requerimentos nutricionais, bioquímica, sorologia e análise genômica, o nome da espécie foi homologado como sendo Spiroplasma kunkelii (WHITCOMB et al., 1986). Seu isolamento em meio de cultura e o preenchimento dos postulados de Koch foi realizado simultaneamente por duas equipes, em 1975 (CHEN; LIAO, 1975; WILLIAMSON; WHITCOMB, 1975). Nos anos subseqüentes, estudos sobre isolamento e composição adequada do meio de cultura foram realizados, o que possibilitou a pesquisadores do mundo todo, o cultivo desse organismo (JONES et al., 1977; LIAO; CHEN, 1977; DAVIS et al., 1984; LEE; DAVIS, 1984; ALIVIZATOS, 1988; LEE; DAVIS, 1989).

Ao contrário do $S$. kunkelii, o fitoplasma associado ao enfezamento vermelho ainda não foi cultivado in vitro. Foi relatado pela primeira vez em plantas de milho, por meio de microscopia eletrônica, em 1969 (GRANADOS, 1969). Pelo fato de não poder ser cultivado em meios de cultura, os postulados de Koch ainda não foram preenchidos para essa doença. Desse modo, estudos de caracterização desse agente ainda estão restritos à testes moleculares e biológicos, envolvendo hospedeiros e vetores.

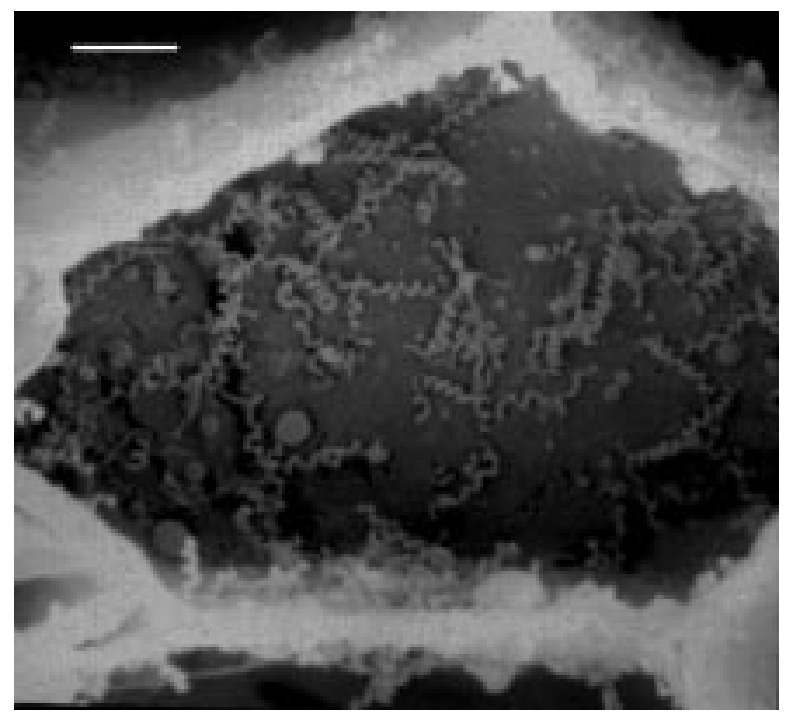

Figura 1 (A) - Micrografia eletrônica de varredura, de folha de milho criofraturada, mostrando um vaso de floema com inúmeros espiroplasmas (barra: 2mm). 


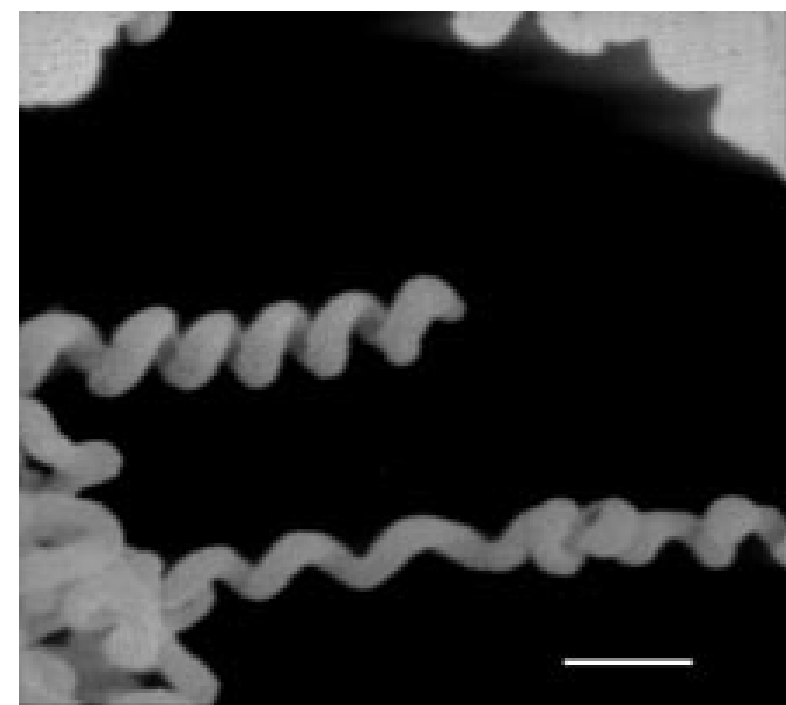

Figura 1 (B) - Detalhe da morfologia helicoidal do $S$. kunkelii (barra: 500 mm). Fotos: Nelson S. Massola Jr. e Elliot W. Kitajima.

\section{Transmissão}

Os dois patógenos são transmitidos pela cigarrinha do milho (Dalbulus maidis DeLONG \& WOLCOTT), de maneira persistente propagativa (NAULT, 1980). Este tipo de relação entre patógeno e vetor é, geralmente, caracterizado pela existência de períodos bem definidos envolvendo esta associação. O período de aquisição é definido como sendo o tempo necessário para que o vetor adquira o patógeno, ao se alimentar na planta fonte infectada; o período de incubação ou de latência é o tempo necessário para que o patógeno colonize os tecidos internos do vetor, até atingir as glândulas salivares, momento em que o inseto estará apto a transmiti-lo; o período de inoculação é o tempo que o vetor deve se alimentar numa planta sadia para que haja transmissão do patógeno e, finalmente, o período de retenção refere-se ao tempo em que o inseto permanece capaz de transmitir o patógeno (NAULT, 1997). $\mathrm{Na}$ associação entre os agentes causais dos enfezamentos e a cigarrinha $D$. maidis, os períodos de aquisição, incubação e inoculação, variam, respectivamente, de 4 a 7 dias, 13 a 24 dias e 2 a 7 dias. O período de retenção é longo, e o inseto normalmente transmite os agentes por toda a vida. Entretanto, a eficiência na transmissão pode decrescer com o aumento da idade do vetor (DAVIS, 1974; TSAI, 1979; NAULT, 1980; MADDEN; NAULT, 1983). A duração dos períodos de aquisição, incubação e inoculação influencia na proporção final de insetos infectivos e na transmissão. No geral, à medida em que são aumentados os períodos de aquisição e incubação, aumenta-se a proporção de insetos infectivos e, à medida que se aumenta o período de inoculação, ocorre um aumento na taxa de transmissão (ALIVIZATOS; MARKHAM, 1986; LEGRAND; POWER, 1994). Além da cigarrinha $D$. maidis, principal vetor, tem-se demonstrado, experimentalmente, que outras espécies, a exemplo de Dalbulus eliminatus, $D$. gelbus, D. guevarai, D. quinquenotatus, D. tripsacoides, Baldulus tripsaci, Exitianus exitiosus, Graminella nigrifons e Stirellus bicolor, são capazes de transmitir, com eficiência variável, os agentes dessas doenças (GRANADOS; WHITCOMB, 1971; CHOUDHURY; ROSENKRANZ, 1973; NAULT, 1980; MADDEN; NAULT, 1983). No Brasil, Dalbulus maidis tem sido relatada como a única espécie do gênero encontrada em milho (OLIVEIRA, 1996). Como essa espécie é vetora dos dois agentes causais, é comum encontrar plantas exibindo ambas as doenças ao mesmo tempo no campo, e assim a designação de "complexo enfezamento" para esses casos.

\section{Sintomas}

O sintoma inicial de infeção por espiroplasma ou fitoplasma é uma clorose, nas margens das folhas do cartucho, com algum grau de avermelhamento das pontas das folhas mais velhas. A partir deste, a literatura registra diferenças nos sintomas entre plantas infectadas com espiroplasma (enfezamento pálido) e fitoplasma (enfezamento vermelho). Sintomas mais adiantados do enfezamento pálido surgem como pontos e estrias cloróticas bem delimitadas, próximas à base das folhas. Sintomas como avermelhamento foliar e perfilhamento da planta são associados ao fitoplasma. Outros sintomas, como redução no tamanho da planta e proliferação de espigas são atribuídos a ambos os patógenos indistintamente (SHURTLEFF, 1986). Entretanto, Nault (1980) demonstrou que o quadro sintomatológico das plantas afetadas pelos enfezamentos, além dos agentes causais, depende do genótipo do hospedeiro e do ambiente. Com exceção dos sintomas de estrias cloróticas na base das folhas, que invariavelmente estão associados ao espiroplasma, os demais sintomas não permitem uma associação segura com o agente causal. Confirmando essa constatação, Bajet e Renfro (1989), verificaram a presença de $S$. kunkelii em plantas com sintomas de avermelhamento ou amarelecimento foliar. Aparentemente, o fitoplasma é predominante sobre o espiroplasma na manifestação de sintomas. Silva et al. (2001) relataram que, em plantas com infecção dupla, os sintomas mais evidentes geralmente são os do enfezamento vermelho, apesar da presença simultânea dos dois patógenos. O mesmo pode ocorrer em relação aos danos à produção. Massola Júnior et al. (1999) verificaram reduções de aproximadamente $70 \%, 50 \%$ e $20 \%$ na produção em plantas inoculadas, respectivamente, com fitoplasma, fitoplasma + espiroplasma e espiroplasma.

\section{Diagnose}

Pela complexidade na sintomatologia, a diagnose correta dos enfezamentos pálido e vermelho necessita de testes refinados. Estudos têm revelado a utilidade da microscopia ótica, associada ao uso de determinados corantes, para fins de diagnose (DEELEY et al., 1979; OVERMAN et al., 1992). Porém, esses estudos apenas confirmam a infecção por molicutes, sem entretanto identificar se o agente causal é o espiroplasma ou o fitoplasma. A microscopia eletrônica de transmissão ou varredura, pelo seu poder de resolução, tem auxiliado na detecção precisa desses organismos 
(KITAJIMA; COSTA, 1979; BRADFUTE et al., 1981; KITAJIMA; NAZARENO, 1985; KITAJIMA, 1994; MASSOLA JÚNIOR; KITAJIMA, 1997). Entretanto, a distribuição irregular dos patógenos nos tecidos da planta infectada (DAVIS, 1995b; GUSSIE et al., 1995), mais a pequena secção de tecido utilizada, tornam a microscopia eletrônica, método pouco prático para diagnose em larga escala. Assim, outros métodos de diagnose tem sido desenvolvidos com essa finalidade.

Como o espiroplasma pode ser cultivado em meios sintéticos, torna-se fácil a obtenção de antisoro para este agente, fazendo com que o teste ELISA ("enzyme-linked immunosorbent assay") seja largamente utilizado para a sua detecção (RAJU; NYLAND, 1981; EDEN-GREEN, 1982; GORDON et al., 1985). Para os fitoplasmas, o teste ELISA não tem sido muito empregado, pela dificuldade na obtenção do antisoro. Entretanto, alguns estudos envolvendo antisoro monoclonal têm permitido diagnoses seguras (LIN; CHEN, 1985; CHEN; JIANG, 1988).

Desde a descoberta dos fitoplasmas (previamente conhecidos como "mycoplasmalike organisms" - MLOs) por uma equipe de pesquisadores japoneses, em 1967 (DOl et al., 1967), a diagnose desses agentes de doenças de plantas têm sido feitas por meio de microscopia eletrônica e, testes biológicos, a exemplo, gama de hospedeiros vetores e sintomas em diferentes espécies vegetais etc. Entretanto, as propriedades biológicas desses agentes podem levar a conclusões enganosas. Modernas técnicas biotecnológicas, particularmente aquelas envolvendo amplificação de determinadas seqüências do RNA ribossômico, têm auxiliado na solução desse problema (DAVIS, 1995a, 1995b). A técnica de PCR ("polymerase chain reaction"), por ser relativamente simples e muito sensível, tem sido largamente utilizada pelos pesquisadores na detecção de fitoplasmas em plantas e vetores (DAVIS; LEE, 1993; VEGA et al., 1993; LEE et al., 1993; HARRISON et al., 1996; LOPES et al., 1997). Recentemente foi verificado, por meio de PCR e RFLP, que o fitoplasma que causa o enfezamento vermelho do milho no Brasil é geneticamente similar ao agente da doença conhecida como "Maize Bushy Stunt" (MBS) nos EUA (BEDENDO et al., 1997).

\section{Controle}

Os cultivos de milho "safrinha", geralmente são mais afetados por essas doenças devido a fatores predisponentes no início da implantação dessas culturas, como elevadas temperaturas e populações do vetor. Assim, uma das medidas de controle preconizadas consiste em evitar este tipo de plantio. No entanto, a "safrinha" é prática amplamente adotada nas principais regiões produtoras do Brasil. O emprego de genótipos resistentes tem sido a melhor recomendação para minimizar os prejuízos causados pelas duas formas do enfezamento (ULLSTRUP, 1978; SHURTLEFF, 1986; PEREIRA, 1997, BASSO; MIRANDA FILHO, 2001). A resistência de genótipos de milho aos enfezamentos foi estudada por alguns pesquisadores por volta de 1970 e parece ser condicionada por vários genes. Grogane Rosenkranz (1968) observaram que não houve dominância para resistência ou suscetibilidade ao enfezamento, porém os efeitos aditivos foram evidentes. Nelson e Scott (1973), através de cruzamentos dialélicos entre 5 linhagens suscetíveis e 5 resistentes, verificaram que os efeitos aditivos na herança da resistência ao enfezamento foram muito mais pronunciados que a dominância. Numa escala de avaliação de 1 (resistente) a 6 (altamente suscetível), obtiveram valores médios de 1,6, 2,4 e 3,5 para os cruzamentos resistente $X$ resistente, resistente $X$ suscetível e suscetível X suscetível, respectivamente. Em outro estudo, Scott e Rosenkranz (1974) observaram que os genes que condicionam resistência aos enfezamentos e ao mosaico anão do milho, doença causada por vírus, não são os mesmos. A resistência a estas duas doenças foi herdada independentemente.

Além do emprego de genótipos resistentes, estudos para controle do enfezamento baseados em outras medidas tem sido realizados. Práticas agrícolas têm sido avaliadas, a exemplo das alterações no nível de nitrogênio, densidade de semeadura e emprego de outras culturas em consórcio com o milho. Estas práticas baseiam-se na hipótese de que o nível de nitrogênio, a densidade de semeadura e a presença de culturas intercalares, modificam o ambiente de cultivo o qual influencia na abundância, atividade e movimento dos insetos vetores. Como conseqüência, a dispersão dos patógenos veiculados por $D$. maidis também seria influenciada. Entretanto, os escassos estudos realizados para avaliar essa hipótese não têm mostrado efeitos pronunciados na redução da incidência dos enfezamentos. Estudos realizados na Nicarágua (POWER, 1987; 1989), mostraram tendências para menores populações de $D$. maidis em parcelas com níveis menores de nitrogênio e maiores densidades de semeadura. Nessas parcelas, a incidência de enfezamento também apresentou tendência em ser menor, porém, a análise estatística dos resultados mostrou que muitas destas tendências não foram significativas. Estudos conduzidos na Costa Rica (CASTRO et al., 1992), mostraram que, nem a densidade de plantio nem a presença de uma cultura intercalar exercem influência marcante no movimento de $D$. maidis e na disseminação de patógenos veiculados por este vetor.

O controle químico do inseto vetor foi estudado no início da década de 70, com emprego de inseticidas sistêmicos aplicados no sulco de semeadura (BHIRUD; PITRE, 1972). Entre os inseticidas avaliados, carbofuran foi o mais eficiente, em casa de vegetação e no campo. O controle de $D$. maidis com este inseticida, em campo, levou a uma redução de cerca de $84 \%$ na incidência do enfezamento nas plantas. Embora Oliveira et al. (1997) citem que é possível o controle químico de $D$. maidis, especialmente em campos de produção de sementes, são escassos os estudos dessa natureza nas condições do Brasil. 


\section{Referências}

AGRIOS, G.N. Plant diseases caused by prokariotes: bacteria and mollicutes. In: AGRIOS, G.N. (Ed.). Plant Pathology. 4.ed. San Diego: Academic Press, 1997. cap. 12, p. $407-470$.

ALIVIZATOS, A.S. Isolation and culture of corn stunt spiroplasma in serum-free medium. Journal of Phytopathology, v.122, p. 68-75, 1988.

ALIVIZATOS, A.S.; MARKHAM, P.G. Acquisition and transmission of corn stunt spiroplasma by its leafhopper vector Dalbulus maidis. Annals of Applied Biology, v. 108, p. 535-544, 1986.

ALMEIDA, T.C. Utilização do milho e do sorgo no Brasil. In: BÜLL, L. T.; CANTARELLA, H. (Ed). Cultura do milho: fatores que afetam a produtividade. Piracicaba: Associação Brasileira para Pesquisa da Potassa e do Fosfato, 1993. cap. 2, p. 11-21.

ALTSTATT, G.E. A new corn disease in the Rio Grande valley. Plant Disease Reporter, v.29, p.533-534, 1945.

ANUÁRIO ESTATíSTICO DO BRASIL - 1973, v.36, p.161, 1975.

ANUÁRIO ESTATÍSTICO DO BRASIL - 1993, v.55, p.3-39, 1995.

BAJET, N.B.; RENFRO, B.L. Occurrence of corn stunt spiroplasma at different elevations in Mexico. Plant Disease, v.73, p. 926-930, 1989.

BASSO, C.W.; MIRANDA FILHO, J.B. Médias preditas de produção de compostos de milho sob severa epidemia de enfezamento no sudeste do Brasil. Summa Phytopathologica, Jaboticabal, v. 27, n. 1, p. 23-30, 2001.

BEDENDO, I.P. Micoplasmas e espiroplasmas. In: BERGAMIN FILHO, A., KIMATI, H., AMORIM, L. (Ed.) Manual de fitopatologia: princípios e conceitos. 3.ed. São Paulo: Agronômica Ceres, 1995. Cap.9, p. 202-210.

BEDENDO, I.P., DAVIS, R.E.; DALLY, E.L. Molecular evidence for the presence of maize bushy stunt phytoplasma in corn in Brazil. Plant Disease, v.81, p.957, 1997.

BHIRUD, K.M.; PITRE, H.N. Bioactivity of systemic insecticides in corn: relationships to leafhopper vector control and corn stunt disease incidence. Journal of Economic Entomology, v.65, p.1134-1140, 1972.

BRADFUTE, O.E; TSAI, J.H.; GORDON, D.T. Corn stunt spiroplasma and viruses associated with a maize disease epidemic in southern Florida. Plant Disease, v. 65, p.837841, 1981

CASTRO, V. et al. The influence of weather and microclimate on Dalbulus maidis (Homoptera: Cicadellidae) flight activity and the incidence of diseases within maize and bean monocultures and bicultures in tropical America. Annals of Applied Biology, v.121, p. 469-482, 1992.

CHEN, T.A.; GRANADOS, R.R. Plant pathogenic mycoplasma-like organism: maintenance in vitro and transmission to Zea mays L. Science, v.167, p.1633-1636, 1970.

CHEN, T.A.; JIANG, X.F. Monoclonal antibodies against the maize bushy stunt disease agent. Canadian Journal of Microbiology, v.34, p.6-11, 1988.

CHEN, T.A.; LIAO, C.H.. Corn stunt spiroplasma: isolation, cultivation, and proof of pathogenicity. Science, v.188, p.10151017, 1975.
CHOUDHURY, M.M.; ROSENKRANZ, E. Differential transmission of Mississippi and Ohio corn stunt agents by Graminella nigrifons. Phytopathology, v.63, p.127-133, 1973.

COSTA, A.S.; KITAJIMA, E.W.; ARRUDA, S.C. Moléstias de vírus e de micoplasma do milho em São Paulo. Revista da Sociedade Brasileira de Fitopato-logia, v.4, p.39-41, 1971.

DAVIS, M.J.; TSAI, J.H.; McCOY, R.E. Isolation of the corn stunt spiroplasma from maize in Florida. Plant Disease, v. 68, p.600-604, 1984.

DAVIS, R. E. Spiroplasma in corn stunt-infected individuals of the vector leafhopper Dalbulus maidis. Plant Disease Reporter, v.58, p.1109-1112, 1974.

DAVIS, R.E. New perspectives on yellows diseases and their causal agents gained through molecular methods for pathogen detection and identification. Summa Phytopathologica, v.21, p.86-87, 1995b.

DAVIS, R.E. Occurrence of a spiroplasma in corn stuntinfected plants in Mexico. Plant Disease Reporter, v.57, p.333337, 1973.

DAVIS, R.E. Fitoplasmas: fitopatógenos procarióticos sem parede celular, habitantes de floema e transmitidos por artrópodes. Revisão Anual de Patologia de Plantas, v.3, p.1-27, 1995a.

DAVIS, R.E.; LEE, I.M. Cluster-specific polymerase chain reaction amplification of $16 \mathrm{~S}$ rDNA sequences for detection and identification of mycoplasmalike organisms. Phytopathology, v.83, n.9, p.1008-1011, 1993.

DAVIS, R.E.; WORLEY, J.F. Spiroplasma: motile, helical microorganism associated with corn stunt disease. Phytopathology, v.63, p.403-408, 1973.

DAVIS, R.E. et al. Helicoidal filaments produced by a mycoplasma-like organism associated with corn stunt disease. Science, v.176, p.521-523, 1972.

DEELEY, J.; STEVENS, W.A.; FOX, R.T.V. Use of Diene's stain to detect plant diseases induced by mycoplasmalike organisms. Phytopathology, v.69, p.1169-1171, 1979.

DOI, Y. et al. Mycoplasma or PLT-like organisms found in the phloem elements of plants infected with mulberry dwarf, potato witches' broom, aster yellows and Paulownia witches' broom. Annals of the Phytopathologycal Society of Japan, v. 33, p. 259-266, 1967.

DUARTE, A.P. Milho - como fazer uma boa segunda safra. Cultivar, Porto alegre, v. 3, n. 25, p. 10-18, 2001.

EDEN-GREEN, S.J. Detection of corn stunt spiroplasma in vivo by ELISA using antisera to extracts from infected corn plants (Zea mays). Plant Pathology, v. 31, p.289-297, 1982.

FERNANDES, F.T.; BALMER, E. Situação das doenças de milho no Brasil. Informe Agropecuário, Belo Horizonte, v. 14, n. 165, p. 35-37, 1990.

GERAGE, A.C.; BIANCO, R. A produção de milho na "safrinha". Informe Agropecuário, Belo Horizonte, v. 14, n. 164, p. 39-44, 1990.

GORDON, D.T. et al. Serological detection of corn stunt spiroplasma and maize rayado fino virus in field-colected Dalbulus spp. from Mexico. Plant Disease, v.69, p.108$111,1985$. 
GRANADOS, R.R. Electron microscopy of plants and insect vectors infected with the corn stunt disease agent. Contributions of the Boyce Tompsom Institute, v.24, p.173187, 1969.

GRANADOS, R.R.; WHITCOMB, R.F. Transmission of corn stunt mycoplasma by the leafhopper Baldulus tripsaci. Phytopathology, v.61, p.240-241, 1971.

GROGAN, C.O.; ROSENKRANZ, E.E. Genetics of host reaction to corn stunt virus. Crop Science, v. 8, p. 252-254, 1968.

GUSSIE, J.S.; FLETCHER, J.; CLAYPOOL, P.L. Movement and multiplication of Spiroplasma kunkelii in corn. Phytopathology, v. 85, p. 1093-1098, 1995.

HARRISON, N.A. et al. PCR assay for detection of the phytoplasma associated with maize bushy stunt disease. Plant Disease, v. 80, p. 263-269, 1996.

HRUSKA, A.J.; GLADSTONE, S.M.; OBANDO, R. Epidemic roller coaster: maize stunt disease in Nicaragua. American Entomologist, v.42, p.248-252, 1996.

JONES, A.L. et al. Comparative growth and primary isolation of spiroplasmas in media based on insect tissues culture formulations. Phytopathology, v. 67, p. 738-746, 1997.

KITAJIMA, E.W. Enfermidades de plantas associadas a organismos do tipo micoplasma. Revisão Anual de Patologia de Plantas, Passo Fundo, v. 2, p. 153-174, 1994

KITAJIMA, E.W.; COSTA, A.S. Microrganismos do tipo micoplasma associados a moléstias do tipo amarelo em algumas plantas cultivadas e ornamentais, no estado de São Paulo e no Distrito Federal. Fitopatologia Brasileira, v.4, p.317-327, 1979.

KITAJIMA, E.W.; NAZARENO, N.R.X. Levantamento de vírus e mollicutes do milho no estado do Paraná. Fitopatologia Brasileira, v.10, p.613-625, 1985.

LASTRA, R.; TRUJILLO, G.E. Enfermedades del maiz en Venezuela causadas por virus y micoplasmas. Agronomia Tropical, v.26, p. 441-455, 1976.

LEE, I.-M.; DAVIS, R.E. New media for rapid growth of Spiroplasma citri and corn stunt spiroplasma. Phytopathology, v.74, p.84-89, 1984.

LEE, I.-M.; DAVIS, R.E. Serum-free media for cultivation of spiroplasmas. Canadian Journal of Microbiology, v.35, p.1092-1099, 1989.

LEE, I.-M. et al. Universal amplification and analysis of pathogen 16S rDNA for classification and identification of mycoplasmalike organisms. Phytopathology, v.83, p.834842, 1993

LEGRAND, A.I.; POWER, A.G. Inoculation and acquisition of maize bushy stunt mycoplasma by its leafhopper vector Dalbulus maidis. Annals of Applied Biology, v. 125, p. 115122, 1994

LEZCANO, R.; MACHADO, V. Fitoplasmas y espiroplasmas de maiz en el Paraguay. Fitopatologia Brasileira, v.22, p.347, 1997.

LIAO, C.H.; CHEN, T.A. Culture of corn stunt spiroplasma in a simple medium. Phytopathology, v.67, p.802-807, 1977.

LIN, C.P.; CHEN, T.A. Monoclonal antibodies against the aster yellows agent. Science, v. 227, p. 1233-1235, 1985.

LOPES, M.T.V.C. et al. Freqüência de mollicutes associados ao enfezamento do milho em algumas localidades do estado de São Paulo. Fitopatologia Brasileira, v.22, p. 347, 1997.
MADDEN L.V.; NAULT. L.R. Differential pathogenicity of corn stunting mollicutes to leafhopper vectors in Dalbulus and Baldulus species. Phytopathology, v.73, p.1608-1614, 1983.

MAGALHÃES, P.C.; DURÃES, F.O.M.; PAIVA, E. Fisiologia da planta de milho. Sete Lagoas: Empresa Brasileira de Pesquisa Agropecuária - EMBRAPA, 1995. 64p. (EMBRAPA. Circular Técnica, 20).

MARAMOROSCH, K. Cross protection between two strains of corn stunt virus in a insect vector. Virology, v.6, p.448459, 1958

MASSOLA JR., N.S. et al. Effects of inoculation time of corn with Spiroplasma kunkelii on yield components. Fitopatologia Brasileira, Brasília, v. 24, n. 4, p. 570-573, 1999b.

MASSOLA JR., N.S. BEDENDO, I.P., AMORIM, L. \& LOPES, J.R.S. Fitoplasma e espiroplasma em milho: multiplicação e efeito na produção de genótipos resistente e suscetível. Summa Phytopathologica, Jaboticabal, v. 25, n. 4, p. 356359, 1999c.

MASSOLA JR., N.S. et al. Quantificação de danos causados pelo enfezamento vermelho e enfezamento pálido do milho em condições de campo. Fitopatologia Brasileira, Brasília, v. 24, n. 2, p. 136-142, 1999a.

MASSOLA JÚNIOR, N.S.; KITAJIMA, E.W. Scanning electron microscopy and in situ immunolabelling of the corn stunt spiroplasma. Acta Microscopica, v.6, p.176-177, 1997.

NAULT, L.R. Arthropod transmission of plant viruses: a new synthesis. Annals of the Entomological Society of America, v.90, p.521-541, 1997.

NAULT, L.R. Maize bushy stunt and corn stunt: a comparison of disease symptoms, pathogen host ranges, and vectors. Phytopathology, v.70, p.659-662, 1980.

NAULT, L.R.; GORDON, D.T.; CASTILLO LOAYZA, J. Maize virus and mycoplasma diseases in Peru. Tropical Pest Management, v.27, p.363-369, 1981.

NAULT, L.R. et al. Identification of maize viruses and Mollicutes and their potential insect vectors in Peru. Phytopathology, v.69, p.824-828, 1979.

NELSON, L.R.; SCOTT, G.E. Diallel analysis of resistance of corn (Zea mays L.) to corn stunt. Crop Science, v.13, p.162-164, 1973.

OLIVEIRA, C.M. Variação morfológica entre populações de Dalbulus maidis (DeLong \& Wolcott, 1923) (Hemiptera:Cicadellidae) de algumas localidades do Brasil. Piracicaba - SP, 1996. 69 p. Dissertação (Mestrado) - Escola Superior de Agronomia "Luiz de Queiroz" - ESALQ/ USP.

OLIVEIRA, E. et al. "Enfezamento pálido" e "enfezamento vermelho" na cultura do milho no Brasil Central. Fitopatologia Brasileira, v.23, p.45-47, 1998.

OLIVEIRA, E.; WAQUIL, J.M.; PINTO, N.F.J.A. Doenças causadas por patógenos transmitidos por insetos: complexo enfezamento/mosaico. In: SEMINÁRIO SOBRE A CULTURA DO MILHO "SAFRINHA", 4, Assis, 1997. Anais. Assis: IAC/CDV, 1997. p.87-94.

OVERMAN, M.A.; KO, N.J.; TSAI, J.H. Identification of viruses and mycoplasmas in maize by use of light microscopy. Plant Disease, v.76, p.318-322, 1992.

PEREIRA, O.A.P. Doenças do milho. In: KIMATI, H. et al. (Ed.). Manual de Fitopatologia - doenças das plantas cultivadas. vol 2. São Paulo: Agronômica Ceres, 1997. Cap.52, p. 538-555. 
PINAZZA, L. A. Perspectivas da cultura do milho e do sorgo no Brasil. In: BÜLL, L. T.; CANTARELLA, H. (Ed.). Cultura do milho - fatores que afetam a produtividade. Associação Brasileira para pesquisa da potassa e do fosfato, Piracicaba, 1993. cap. 1, p. 1-10.

POWER, A.G. Influence of plant spacing and nitrogen fertilization in maize on Dalbulus maidis (homoptera: cicadellidae), vector of corn stunt. Environmental Entomology, v.18, p.494-498, 1989.

POWER, A.G. Plant community diversity, herbivore movement, and an insect-transmited disease of maize. Ecology, v.68, p.1658-1669, 1987.

RAJU, B.C.; NYLAND, G. Enzyme-linked immuno-sorbent asay for the detection of corn stunt spiroplasma in plant and insect tissues. Current Microbiology, v.5, p.101-104, 1981.

SCOTT, G.E.; ROSEKRANZ, E.E. Independent inheritance of corn stunt and maize dwarf mosaic in corn. Crop Science, v.14, 104-106, 1974.

SCOTT, G.E.; ROSEKRANZ, E.E.; NELSON, L.R. Yield losses of corn due to corn stunt disease complex. Agronomy Journal, v.69, p.92-4, 1977.

SHURTLEFF, M.C. Compendium of corn diseases. 2 ed. St. Paul: American Phytopathological Society, 1986. 105 p.

SILVA, H.P. et al. Manejo integrado de doenças na cultura do milho safrinha. In: SEMINÁRIO NACIONAL DE MILHO SAFRINHA, 6., 2001. A cultura do milho safrinha. LondrinaPR: IAPAR, 2001. p. 113-144.
SILVA, H.P. et al. Identificação e controle das doenças de milho. Informativo Coopercitrus, v. 6, n. 61, p. 18-24, 1991.

TSAI, J.H. Vector transmission of mycoplasmal agents of plants diseases. In: WHITCOMB, R.F.; TULLY, J.G. (Eds.). The mycoplasmas: Plant and insect mycoplasmas. Vol. III. New York: Academic Press, 1979. cap. 9, p.265-307.

TSUNECHIRO, A.; GODOY, R.C.B. Histórico e perspectivas do milho safrinha no Brasil. In: SEMINÁRIO NACIONAL DE MILHO SAFRINHA, 6., 2001. A cultura do milho safrinha. Londrina-PR: IAPAR, 2001. p. 1-10.

ULLSTRUP, A.J. Corn diseases in the United States and their control. Washington, D.C.: USDA, 1978. 55p. (USDA. Agriculture Handbook, 199).

VEGA, F.E. et al. Detection of a plant pathogen in a nonvector insect species by the polymerase chain reaction. Phytopathology, v.83, p. 621-624, 1993.

WAQUIL, J.M. Amostragem e abundância de cigarrinhas e danos de Dalbulus maidis (DeLong e Wolcott) (Homoptera: Cicadellidae) em plântulas de milho. Anais da Sociedade Entomológica do Brasil, v. 26, n. 1, p. 27-33, 1997.

WHITCOMB, R.F. et al. Spiroplasma kunkelii sp. nov.: characterization of the etiological agent of corn stunt disease. International Journal of Systematic Bacteriology, v.36, p.170-178, 1986.

WILLIAMSON, D.L.; WHITCOMB, R.F. Plant mycoplasmas: a cultivable spiroplasma causes corn stunt disease. Science, v.188, p.1018-1020, 1975. 
